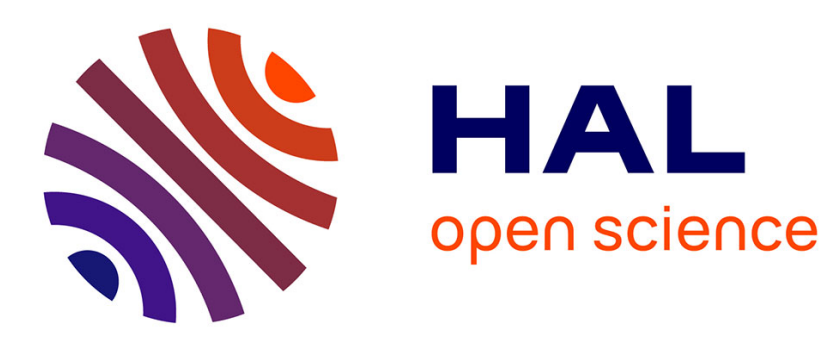

\title{
Friction and wear during twin-disc experiments under ambient and cryogenic conditions
}

Luc Chevalier, S. Cloupet, M. Quillien

\section{To cite this version:}

Luc Chevalier, S. Cloupet, M. Quillien. Friction and wear during twin-disc experiments under ambient and cryogenic conditions. Tribology International, 2006, 39 (11), pp.1376-1387. 10.1016/j.triboint.2005.12.003 . hal-00782485

\section{HAL Id: hal-00782485 \\ https://hal.science/hal-00782485}

Submitted on 29 Jan 2013

HAL is a multi-disciplinary open access archive for the deposit and dissemination of scientific research documents, whether they are published or not. The documents may come from teaching and research institutions in France or abroad, or from public or private research centers.
L'archive ouverte pluridisciplinaire HAL, est destinée au dépôt et à la diffusion de documents scientifiques de niveau recherche, publiés ou non, émanant des établissements d'enseignement et de recherche français ou étrangers, des laboratoires publics ou privés. 
Submitted to Tribology International, Nov. 2004

Revised version, November 2005

Friction and Wear during Twin-disc Experiments under Ambient and Cryogenic

\section{Conditions}

L. Chevalier ${ }^{1 *}$, S. Cloupet ${ }^{1}$, M. Quillien ${ }^{2}$

${ }^{1}$ LaM, Université de Marne la Vallée

5 boulevard Descartes

Champs sur Marne

77454 Marne la Vallée Cedex, France

Tel.: (33) 160957785

Email: 1uc.chevalier@univ-mlv.fr

Email: sylvain.cloupet@univ-mlv.fr

URL: http://www.univ-mlv.fr/lam/lam.htm

${ }^{2}$ ISMEP - LISMMA, 3 rue Fernand Hainaut

93407 St Ouen Cedex - France

Tel: (33) 149452955

Email: muriel.quillien@supmeca.fr

* corresponding author 


\section{Friction and Wear during Twin-disc Experiments under Ambient and Cryogenic Conditions}

L. Chevalier, S. Cloupet, M. Quillien

Abstract: We present a classical rolling contact apparatus where two discs roll and slide under a constant normal loading. Experimental results concerning bearing steel used in ambient air or under severe temperature conditions (Liquid Nitrogen) are presented. A simplified model proposed by Kalker (Fastsim) is used to identify the dynamic friction coefficient between these discs and to study the apparatus parameters influence on dissipated energy. Wear evolution is simulated using classical Archard's law and compared to measured profiles. Influence of ambient conditions is highlighted by comparing friction and wear coefficients. Keywords: Twin-disc experiment, dynamic friction coefficient measurement, wear simulation, Fastsim

\section{Introduction}

Bearing track lubrication limits the dynamic friction coefficient value when the bearing balls are loaded. Consequently, the wear which results from this friction is also limited. In the case of turbopump bearings used in the space shuttle launch engine, the important loading makes this point very sensitive. Moreover, these bearings work in particularly harsh thermal environments since they are bathed in liquid oxygen $(90 \mathrm{~K})$ or liquid hydrogen $(20 \mathrm{~K})$. At such temperatures one is interested to know the effects of friction and wear. Because it is very difficult to manage lubrication at this temperature, our goal is to study the influence of the temperature on dynamic friction coefficient and wear factor in the absence of lubrication. 
Twin disc apparatus is used to perform dynamic friction coefficient evolution measurements under constant normal load and variable slip (see Quillien \& al. [1]). After testing, information on wear may be obtained. In this study we focus on modelling the experiment in order to evaluate dynamic friction coefficient and wear factor for the two situations: ambient temperature and cryogenic conditions $\left(-196^{\circ} \mathrm{C}\right)$.

First, we briefly recall the mechanical problem to solve and estimate the tangential force during the twin-disc experiment. Then we compare the experimental results to the simulation in order to discuss: (i) the evolution of the apparent friction coefficient versus longitudinal slip; (ii) the influence of temperature on coefficient of friction. Afterwards, we present the wear measurements and recall Archard's law used for simulation. An updated Hertzian approach is used to take into account the wear profile evolution. Finally, we discuss the results of the simulation and make conclusions on the wear factor value in cryogenic or ambient air.

\section{Dynamic friction coefficient identification}

\subsection{Twin-disc apparatus description}

A twin-disc experiment is performed on two steel specimens (Fig.1) under extremely different conditions: ambient air at room temperature and cryogenic conditions (specimens are cooled with liquid nitrogen at $-196^{\circ} \mathrm{C}$ in cryostat box). Different rotating rates are imposed at each disc (controlling the rotate velocity of each brushless motor independently) to insure the same rolling velocity $V=R_{1} \omega_{1}=R_{2} \omega_{2}$ or to impose a relative slip. Two belt-driven mechanical spindles, each of which supports $60 \mathrm{~mm}$ diameter specimen disks. $R_{1}$ and $R_{2}$ are equal to 30 $\mathrm{mm}$ and $\omega_{1}$ and $\omega_{2}$ rotate at $3000 \mathrm{rpm}$. This leads to $V$ about $9.5 \mathrm{~m} / \mathrm{s}$. Disc 1 is a cylinder but disc 2 is a portion of a sphere and presents a radius $R_{b}=30 \mathrm{~mm}$ at the contact zone. Each disc is in X105CrMo17 (AISI 440C in American designation) stainless steel. 
Relative slip is imposed at the theoretical contact point between discs and Fig. 2 shows the traction coefficient defined by $T / N$ versus longitudinal creepage (slip rate) $v_{x}$ as defined by Eq. 1 which increases regularly from 0 to $9 \%$. At each step, slip is maintained to insure stability of $T$ measurement.

$v_{x}=\frac{R_{1} \omega_{1}-R_{2} \omega_{2}}{V_{\text {mean }}} \quad$ with $\quad V_{\text {mean }}=\frac{R_{2} \omega_{2}+R_{1} \omega_{1}}{2}$

One notices Fig. 2 that $T / N$ increases for small $v_{x}$ values, for higher values the ratio reaches a quite stable value $\mu=0.6$ at ambient temperature. Under cryogenic conditions the behaviour evolves differently. First, for small $v_{x}$ values the influence of temperature is obvious and dynamic friction coefficient reaches 0.05 . The reduction of friction for low temperature is really significant. When creepage reaches $3 \%$ dynamic friction coefficient increases to the same value reached for ambient temperature. The benefit of cryogenic condition disappears. In order to explain the influence of longitudinal creepage on dynamic friction coefficient one must be sure that $T / N$ is equal to dynamic coefficient of friction. It would equal the real dynamic friction coefficient if slip were occurring over the entire contact area. In the following, $T / N$ ratio will be called the apparent dynamic coefficient of friction.

\subsection{Theoretical basis}

In this section, we focus on the rolling contact analysis. We briefly recall the kinematics relations and friction laws to be solved. Then we present the exact problem and the simplified one that we use for the numerical developments. In the case of two rigid bodies in contact at point $\mathrm{O}(x=0, y=0)$, the rigid sliding velocity $\overrightarrow{V_{r s}}$ is defined by system 2 :

$\left\{\begin{array}{l}V_{r s x}=R_{2} \omega_{2}-R_{1} \omega_{1}+y \varphi_{x} \omega_{2} \\ V_{r s y}=-R_{2} \varphi_{z} \omega_{2}-x \varphi_{x} \omega_{2}\end{array}\right.$ 
Where $V_{r s x}$ and $V_{r s y}$ are the x-coordinate and y-coordinate of $\overrightarrow{V_{r s}}, \varphi_{x}$ and $\varphi_{z}$ are angular defects between the two bodies. Since bodies have an elastic behaviour, the relative velocity has a complementary term and system 2 becomes:

$$
\left\{\begin{array}{l}
w_{x}=R_{2} \omega_{2}-R_{1} \omega_{1}+y \varphi_{x} \omega_{2}-V \frac{\partial u(x, y)}{\partial x} \\
w_{y}=-R_{2} \varphi_{z} \omega_{2}-x \varphi_{x} \omega_{2}-V \frac{\partial v(x, y)}{\partial x}
\end{array}\right.
$$

Where $\vec{w}(x, y)$ is the sliding velocity between two elastic bodies and $w_{x}$ and $w_{y}$ its components. $u(x, y)$ and $v(x, y)$ are the relative displacements in $\mathrm{x}$-direction and y-direction. $w$ can be divided by $V$ and system (3) becomes:

$$
\left\{\begin{array} { l } 
{ \frac { w _ { x } } { V } = v _ { x } - y \phi - \frac { \partial u ( x , y ) } { \partial x } } \\
{ \frac { w _ { y } } { V } = v _ { y } + x \phi - \frac { \partial v ( x , y ) } { \partial x } }
\end{array} \text { with } \left\{\begin{array}{l}
v_{y}=-\frac{R_{2} \varphi_{z} \omega_{2}}{V} \\
\phi=\frac{\varphi_{x} \omega_{2}}{V}
\end{array}\right.\right.
$$

$v_{x}$ and $v_{y}$ are called longitudinal ( $v_{x}$ is also usually called "slip rate") and lateral creepages, $\phi$ is the spin in the contact area and $V$ is the speed of the theoretical contact point when bodies are supposed to be perfectly rigid. In our case, we want to know the tangential traction $\vec{\tau}(x, y)$, the normal load $p(x, y)$ and the sliding velocity $\vec{w}(x, y)$ in the contact area. This problem can be solved with two approaches: first is the exact theory and the second is the simplified theory. According to the Coulomb's friction laws (Eq. 5), if sliding velocity is equal to zero then the tangential traction is lower than friction coefficient multiplied by normal pressure. Otherwise the tangential traction is equal to friction coefficient multiplied by normal pressure.

$$
\left\{\begin{array}{c}
\vec{w}(x, y)=\overrightarrow{0} \Rightarrow|\vec{\tau}(x, y)| \leq \mu p(x, y) \\
\vec{w}(x, y) \neq \overrightarrow{0} \Rightarrow|\vec{\tau}(x, y)|=\mu p(x, y) \quad \text { and } \vec{\tau}(x, y)=-\frac{\mu p(x, y)}{|\vec{w}(x, y)|} \vec{w}(x, y)
\end{array}\right.
$$

$u, v, w$ are related with $\tau_{x}, \tau_{y}$ and $p$ by the elastic behaviour laws of the two bodies. Since Love [2] first proposed the analytical solution of concentrated loading on a semi infinite elastic 
body, it has been possible to establish relation between normal and tangential traction and the relative displacement in the contact area of two semi-infinite bodies (Johnson [3], Kalker [4], Middlin [5]).

\subsubsection{Initial approach: exact theory}

It has been established (see Jacobson \& Kalker [6] for example) that for two quasi-identical bodies (same elastic material properties: $G$ shear modulus and $v$ Poisson's ratio), normal and tangential problems are uncoupled and relative displacements are related to tractions $\tau_{x}, \tau_{y}$ and $p$ by relations in Eq. 6 .

$$
\begin{aligned}
& u(x, y)=\frac{1}{\pi G} \iint_{\text {contact area }}\left(\left\{\frac{1-v}{r}+\frac{v\left(x-x^{\prime}\right)^{2}}{r^{3}}\right\} \tau_{x}\left(x^{\prime}, y^{\prime}\right)+\frac{v\left(x-x^{\prime}\right)\left(y-y^{\prime}\right)}{r^{3}} \tau_{y}\left(x^{\prime}, y^{\prime}\right)\right) d x^{\prime} d y^{\prime} \\
& v(x, y)=\frac{1}{\pi G} \iint_{\text {contact area }}\left(\frac{v\left(x-x^{\prime}\right)\left(y-y^{\prime}\right)}{r^{3}} \tau_{x}\left(x^{\prime}, y^{\prime}\right)+\left\{\frac{1-v}{r}+\frac{v\left(y-y^{\prime}\right)^{2}}{r^{3}}\right\} \tau_{y}\left(x^{\prime}, y^{\prime}\right)\right) d x^{\prime} d y^{\prime} \\
& w(x, y)=\frac{1-v}{\pi G} \iint_{\text {contact area }} \frac{p\left(x^{\prime}, y^{\prime}\right)}{r} d x^{\prime} d y^{\prime}
\end{aligned}
$$

Global $G$ and $v$ are defined from the elastic coefficients for each body by:

$$
\frac{1}{G}=\frac{1}{2 G_{1}}+\frac{1}{2 G_{2}} \quad ; \quad \frac{v}{G}=\frac{v_{1}}{2 G_{1}}+\frac{v_{2}}{2 G_{2}}
$$

Where $(x, y, z)$ are co-ordinates in $\mathrm{x}$-direction, $\mathrm{y}$-direction and $\mathrm{z}$-direction of point $\mathrm{M}$ and $\left(\mathrm{x}^{\prime}\right.$, $\left.y^{\prime}, z^{\prime}\right)$ the co-ordinates of point M' as presented in Fig 3.

The third relation of Eq.6, in the case of constant curvature in the contact area, is analogous to the Hertz problem. Pressure distribution $p(x, y)$ is elliptic, and contact area is an ellipse where half lengths in both $\mathrm{X}$ and $\mathrm{Y}$ directions are denoted $a$ and $b$ and can be solved separately from the first two relations in Eq. 6. The tangential problem is still coupled with the normal problem by the friction law.

Figure 4 shows the case of the two bodies used for the twin-disc apparatus described previously, with a dynamic friction coefficient $\mu=0.6$ and a longitudinal creepage $v_{x}=0.2 \%$. Tangential traction $\tau_{x}$ and slip $w_{x}$ are plotted. These results are obtained with "CONTACT" 
software developed by Kalker which solves the global system of Eqs. 4, 5 and 6. One can observe that the elliptic region of contact ( $a$ and $b$ ) has the dimensions given by the Hertz formula. One can also clearly see the adhesive zone where $w_{x}$ is equal to zero and the sliding zone where $\tau_{x}$ is equal to $\mu p$. This first approach leads to a long CPU time.

\subsubsection{Second approach: derived from the linear Kalker theory (LKT)}

The second approach is based on FASTSIM algorithm (Kalker [7]) derived from the linear Kalker theory. Simulation of wear evolution during twin-disc testing involves numerous iterations and a simplified but quick algorithm is needed to execute the calculations in a reasonably short CPU time. In the Linear Kalker Theory LKT (when creepages are supposed small or friction coefficient extremely high) then the adhesion area is global $(\vec{w}(x, y)=\overrightarrow{0})$ and one can solve system of Eq. 4 which leads to:

$\left\{\begin{array}{c}u=\left(x-a_{i}\right)\left(v_{x}-y \phi\right) \\ v=\left(x-a_{i}\right) v_{y}+\frac{x^{2}-a_{i}^{2}}{2} \phi\end{array}\right.$ with $a_{i}=a \sqrt{1-\left(\frac{y}{b}\right)^{2}}$

Identification with the $u$ and $v$ expressions in Eq. 6 and Eq. 8 provides the global tangential loading $T_{x}$ and $T_{y}$ and spin moment:

$$
\begin{gathered}
T_{x}=G a b C_{11} v_{x} \\
T_{y}=G a b C_{22} v_{y}+G(a b)^{3 / 2} C_{23} \phi \\
M_{z}=G(a b)^{3 / 2} C_{32} v_{y}+G a b C_{33} \phi
\end{gathered}
$$

Where $C_{i j}$ are given by integrals and only depend on $b / a$ and Poisson's ratio $v$. These values are tabulated as $m$ and $n$ coefficients of the Hertz problem [8]. When creepage values become higher (or when friction is smaller) the LKT is no longer valid. Tangential traction saturates near the rear edge and becomes equal to $\mu p$.

An alternative to the prohibitive CPU time needed by the initial approach is to use the Fastsim algorithm as developed by Kalker. Let's examine the proposed simplifications: the local stiffness is modelled as a linear relation between tangential traction and relative displacements 
$u$ and $v$ (i.e. $u=L . \tau_{x}$. and $v=L . \tau_{y}$ ). The $L$ value depends of $C_{i j}$ coefficient, shear elastic modulus $G$ and ellipse dimensions $a$ and $b$, but we must introduce three values to ensure that the $T_{x}$ and $T_{y}$ components of LKT are identical in the case of global adhesion:

$$
L_{1}=\frac{8 a}{3 C_{11} G} \quad, L_{2}=\frac{8 a}{3 C_{22} G} \quad, \quad L_{3}=\frac{\pi a \sqrt{a / b}}{4 C_{23} G}
$$

The simplified problem to solve is expressed by the relations of Eq.11. It is easy to see that for an elliptic pressure distribution, the slip component will lead to infinity at the rear edge of the contact. This is in contradiction with Fig. 4 and one can solve this problem using a parabolic pressure distribution. This is an approximation that increases the maximum pressure $P_{o}$ for $25 \%$ but gives good agreement in the tangential problem case.

$\left\{\begin{array}{l}\frac{w_{x}}{V L}=\frac{v_{x}}{L_{1}}-\frac{\phi y}{L_{3}}-\frac{\partial \tau_{x}}{\partial x} \\ \frac{w_{y}}{V L}=\frac{v_{y}}{L_{2}}+\frac{\phi x}{L_{3}}-\frac{\partial \tau_{y}}{\partial x}\end{array}\right.$

Solving the system in Eq. 11 leads to an analytical solution when spin is neglected. In the case of $\mu=0.6$ and $v_{x}=0.2 \%$, the solution is plotted in Fig. 5. We have compared the two approaches in Fig. 4 and Fig. 5 and accuracy of the Fastsim solution is satisfactory. Consequently we will solve the Fastsim approximation instead of the exact system in what follows.

\subsection{Dynamic friction coefficient identification}

It has been shown in the previous section that when longitudinal creepage is sufficiently small tangential traction $\tau_{x}$ is not equal to $\mu p$ over the whole contact area. Consequently, summing $\tau_{x}$ on this area gives a tangential global load $T$ in the $X$ direction which is lower than $\mu N$ : the ratio $T / N$ is an apparent friction coefficient denoted $\mu_{a}$. Figure 6 shows this apparent dynamic friction coefficient versus longitudinal creepage for a $\mu$ value set to 0.6 . One can see that 
sliding becomes complete over the contact area for longitudinal creepage higher than $1 \%$. Even if the apparent friction coefficient gives a close approximation, one can see that it does not superpose the measured points. This means that the real dynamic friction coefficient varies for small values of creepage.

To conduct dynamic friction coefficient identification we propose the chart in Fig.7. Each curve is obtained for a constant dynamic friction coefficient $\mu$ varying from 0.05 to 0.7 . The light line separates the small creepage values where an adhesive zone remains (local stick area) on the contact area (in this case the slip is not global), and the higher values of $v_{x}$ where sliding is complete on the contact area and the apparent dynamic friction coefficient is over $98 \%$ of the real value. The light line is obtained by plotting each point where $\mu_{a}$ equals $98 \%$ of $\mu$.

One can see that experimental data always appear on the saturated zone of the apparent dynamic friction coefficient excepted for the very first point in ambient air conditions. In case of cryogenic condition, friction coefficient value is smaller and saturation appears for very small values of longitudinal creepage. In both cases, this means that the sliding area appears to be the total elliptic area of the contact zone for the measured points. Apparent dynamic friction coefficient given by $T / N$ is in fact, the real dynamic coefficient of friction. To summarise our conclusions, the foregoing measurements have shown that:

(i) The dynamic friction coefficient depends on the longitudinal creepage value. For very small values, friction is an increasing function of creepage. This observation may appear to be a strange remark since it is classically admitted that the adhesive friction coefficient is higher than the sliding dynamic coefficient of friction. The steady state rolling calculation cannot provide the static solution so we shall not further discuss on this first remark. 
(ii) For high creepage values the dynamic friction coefficient is quite constant (from 0.55 to 0.62 at ambient temperature and from 0.05 to 0.07 under Liquid Nitrogen).

(iii) Cooling the rolling contact with Liquid Nitrogen reduces significantly the sliding dynamic friction coefficient (about 10 times) but when sliding becomes greater (about $v_{x}=5 \%$ ) the reducing effect of Liquid Nitrogen on the friction coefficient vanishes.

This last remark requires a additional comment. The test has been repeated many times and this "instability" of the friction coefficient always appears more or less at the same creepage value. Some thermal effect may be in competition with the liquid nitrogen cooling. If one could be able to quantify dissipated energy during the test it might be possible to quantify the associated rise of temperature. This is point is developed in the final section.

The stick-slip partition of the contact area in steady state rolling has an impact on dissipated power. Wear occurs and contact profiles fluctuate during the test. In the next section, we will present the updating of the solid curvatures during the twin-disc test and will simulate both wear evolution and temperature increase to conclude on the "instability" presented above. The method used for wear simulation and other very similar methods have already been presented in the literature (see [9], [10], [11] for example).

\section{Wear simulation analysis}

\subsection{Loading history and wear measurement}

During the twin-disc experiment, a constant normal load $\mathrm{N}(\mathrm{N}=72 \mathrm{~N})$ is applied but longitudinal creepage $v_{x}$ and the friction coefficient vary following steps shown on Fig. 8 for the two environments. Each step of $v_{x}$ is imposed for 5 iterations except the two last steps for ambient air. One iteration corresponds to 4200 revolutions of each disc. These diagrams 
present the paths followed in friction coefficient and in longitudinal creepage during simulations in ambient cryogenic and ambient air. In the previous section we identified a friction coefficient value $\mu$ for each one of these steps. Because friction coefficient $\mu$ and longitudinal creepage $v_{x}$ influence dissipated power in the contact surface, they are factors governing wear evolution. It is not surprising to observe that the rolling zone of the discs was modified by the experiment.

Figure 9 shows the profile measured after the experiment for the two environments. One can observe that both depth and width of the wear profile are smaller for ambient cryogenic than for ambient air condition. This is logical if we consider that the dynamic friction coefficient is lower for a considerable duration of the experiment. Nevertheless, the magnitudes of wear depth fall within the same range of values ( $6 \mu \mathrm{m}$ instead of $4.4 \mu \mathrm{m}$ with liquid nitrogen) and the width wear profile are smaller in ambient cryogenic than in ambient air (15.1 mm against $18 \mathrm{~mm}$ ). The values of $v_{x}$ over $3 \%$ greatly effects the wear process. In order to compare both wear evolutions, we performed numerical simulation of the wear process. At each step of the simulation the increase of temperature has been evaluated.

\subsection{Updated Hertzian approach for wear simulation}

A model for material loss due to the cyclic rolling contact loading is provided by Archard's law [12]. A similar form was proposed by Zi Li \& Kalker [11] and the mathematical expression is given by Eq. 12 .

$W=\frac{K}{H} T L$

$W\left(\mathrm{~m}^{3}\right)$ is the volume of wear, $L(\mathrm{~m})$ is the sliding length of the abrasive particle, $T(\mathrm{~N})$ is the tangential load and $H\left(\mathrm{~N} / \mathrm{m}^{2}\right)$ is the material hardness. Micro-hardness have been done and $H$ $=700 \mathrm{Hv}$. In Eq.12, $\mathrm{K}$ is a dimensionless coefficient characteristic of the materials in contact. Simple microscopic interpretation of the "Archard's factor" $K$ is frequently given (see Felder 
[13] or François \& al. [14] for example) which suggests a relation between the factor $K$ and the dynamic friction coefficient $\mu$. In that way, a low dynamic friction coefficient leads to very small wear because of slight dissipated power during slip coupled with a small wear factor. We will test this assumption in the following.

Tangential dissipated work is calculated by the product $T$ times $L$. In an instantaneous form of this model, the wear rate $\left(\mathrm{m}^{3} / \mathrm{s}\right)$ is directly proportional to the dissipated power $P_{d}$ as defined in Eq.13.

$\dot{W}=\frac{K}{H} P_{d}$

$P_{d}$ is not uniformly distributed over the contact area and it is necessary to calculate the tangential surface-traction distribution $\tau$ and the sliding velocity $w_{g}$ at each point on the contact area to specify the distribution of dissipated energy per unit surface. We define the wear depth rate $\dot{u}(\mathrm{~m} / \mathrm{s})$ by Eq. 14 .

$\dot{u}=\frac{d \dot{W}}{d S}=\frac{K}{H} \tau w_{g}$

During a single pass of the roller on the cam track, the increment of the wear depth is obtained by an integration over the time $(\mathrm{t})$ of the wear depth rate from zero to $\Delta t=2 a(y) / V$. Where $V$ is the rolling velocity and $2 a(y)$ is the length of the contact stripe at abscise $y$ as shown in Fig. 10. This yields to the incremental wear depth per roller passage $\delta u / \delta n$ given by Eq. 15 where $P_{l}(y)$ is the dissipated power per unit length.

$\frac{\delta u(y)}{\delta n}=\frac{K}{H V} P_{l}(y)$

$P_{l}(y)$ is calculated by integration over $\mathrm{x}$ (rolling direction) of tangential traction $\tau(x, y)$ times sliding velocity $w(x, y)$. Those quantities are inputs for the wear simulation software. For each step of the simulation (one bar in the Fig.8 chart) wear is calculated from the dissipated power per unit length with Eq.15. The best circle to fit the new profile is determined using a classical 
least square distance method. Principal curvatures are updated and a new Fastsim calculation is carried out. The evolution of wear profile can be estimated step by step.

\subsection{Wear law identification}

The wear factor $K$ is unknown and must be identified from the experimental data. Different methods (Newton-Raphson, Monte-Carlo ...) can be used to manage this identification. We implement the following identification procedure by dichotomy:

(i) $\quad K_{0}$ and $K_{l}$ values are chosen arbitrarily but these two values must include the solution $K$. Then we define the solution $K$ as it being the mean of $K_{0}$ and $K_{l}$.

$$
K=\frac{K_{0}+K_{1}}{2}
$$

The principle of this method is to reduce the interval $\left[K_{0} K_{l}\right]$ to converge and to have the solution $K_{0}=K_{1}=K$

(ii) The wear simulation is managed with the $K$ value defined by Eq. 16 following the conditions defined by Fig. 8 . A wear profile $u_{s}(y)$ is obtained and we define $U_{s}$ as the minimum of $u_{s}(y) . U_{s}$ is compared to the minimum $U_{m}$ of wear measures.

(iii) An error $E_{r}(\%)$ is defined by Eq. 17:

$E_{r}(\%)=\frac{U_{m}-U_{s}}{U_{m}} \times 100$

(iv) If $E_{r}(\%)<1 \%$ then the calculation stops, otherwise if $U_{s}>U_{m} \rightarrow$ the upper limit of the interval $\left[K_{0} K_{l}\right]$ was replaced by $K: K_{l}=K$ otherwise $\rightarrow$ the lower limit of the interval $\left[K_{0} K_{l}\right]$ was replaced by $K: K_{0}=K$ This procedure, summarised in Fig. 11, continues until the condition $E_{r}<1 \%$ is satisfied. Using such a procedure for the ambient air case, we have identified the $K$ value of $9.89 .10^{-4}$. Wear simulation in ambient cryogenic is then carried out. Figure 12 shows the maximum depth of cryogenic conditions is accurately modelled with the same $K$ value. This result is 
important because it shows that the wear process is not influenced by the temperature and only depends on the two materials. We believe that this conclusion must be accepted with caution. We have here an identification obtained from on a global process where large differences occur between the friction coefficient at the beginning of the Liquid Nitrogen test (about 0.05 ) and the second part of the test where the friction coefficient rises up to 0.5.

Figure 12 shows that the wear evolution really begins after $2000 \mathrm{sec}$, which is the moment where the friction coefficient increases and becomes equal to the one measured in ambient air condition. This rise in the friction coefficient in cryogenic conditions may be due to an increase in temperature at the contact point. Therefor then is a need to model the thermal evolution originating from the dissipated power during rolling.

Assuming that the thermal problem is axisymetric and that the temperature is constant over the thickness of the disc, the temperature is only a function of the radius $r$ and time $t$ The heat transfer equation yields to Eq.18.

$\frac{\Delta \bar{T}(t)}{\Delta t}=\frac{1}{\rho C \nu}\left[P_{d}-\lambda \operatorname{Sh}_{c}\left(T_{w}-T_{\infty}\right)\right]$

$\bar{T}$ is the mean temperature inside the disc at time $t, T_{w}$ is the wall temperature on the external radius of the disc $r=R$ and $T_{\infty}$ is the temperature of the external ambient. $C$ is the heat capacity, $v$ is the volume of disc, $\rho$ is the disc density, $S$ is the exchange surface, $\lambda$ is the thermal conductivity and $h_{c}$ is the forced convection exchange coefficient.

In order to estimate the contact temperature during the twin-disc test, we assume that $\bar{T}$ has the same order as $T_{w}$. Eq. 18 can then be solved step by step and yields Eq. 19.

$T_{i+1}=T_{i}+\frac{\Delta t}{\rho C v}\left[P_{d}-\lambda S_{c}\left(T_{i+1}-T_{\infty}\right)\right]$

$T_{i+1}$ is computed at each time step $i$. $T_{\infty}$ will be set to the room temperature for the ambient air test or to $-196^{\circ} \mathrm{C}$ for the cryogenic condition. This calculation of the temperature evolution 
necessitates a previous calculation of the power dissipated by rolling at each step of the iterative numerical simulation managed to compute wear evolution.

The temperature evolution for ambient conditions or cryogenic conditions is given on Fig.13. It appears that the temperature increase during the ambient air test is about $10^{\circ} \mathrm{C}$. One can note that the increase in temperature is nearly the same value as for the cryogenic conditions and cannot explain the instability in the friction coefficient chart. We can observe a fall of temperature near $4500 \mathrm{sec}$. in Fig. 13-b. This fall due to the decrease of the friction coefficient imposed (Fig.8) in cryogenic conditions, and thus this can be explained by the low value of dissipated power in regard of a small temperature growth.

Figure 14 shows that the wear profile obtained by numerical simulation compares favourably the depth of the measured wear profile of the cryogenic test. This is already a good point because the wear factor has been identified from the ambient air test. One can observe that the wear width is too small compared to the measured profile. This is certainly the consequence of the procedure used to update curvatures at each step of the simulation and can be improved by using a non linear wear law or by developing a semi-hertzian procedure as proposed by $\mathrm{Zi}$ Li \& Kalker [15] or by Ayasse \& Chollet [16].

\section{Conclusions}

Experimental data obtained during twin-disc tests managed under ambient air and cryogenic conditions have been analysed using a simplified modelling of steady state rolling. This analysis enables accurate identification of slip influence on the friction ratio between discs. The influence of temperature conditions has also been discussed and it appears that the cooling contact yields to a spectacular decrease of the friction ratio compared to ambient temperature conditions. Unfortunately, this low value is not stable and for 5\% relative slip, the friction coefficient rises to the nearly same value than at ambient temperature. It has been 
shown that dissipation is not responsible for this instability, and at this time there is no explanation for its existence.

Further investigation of the wear evolution that occurs during the test has been provided using a classical Archard model. It appears that using the same wear factor at ambient air or cryogenic conditions enables an accurate prediction of the wear profile depth at the end of the test. Nevertheless, a semi Herztian approach must be implemented to be able to predict also the wear profile width.

\section{Nomenclature}

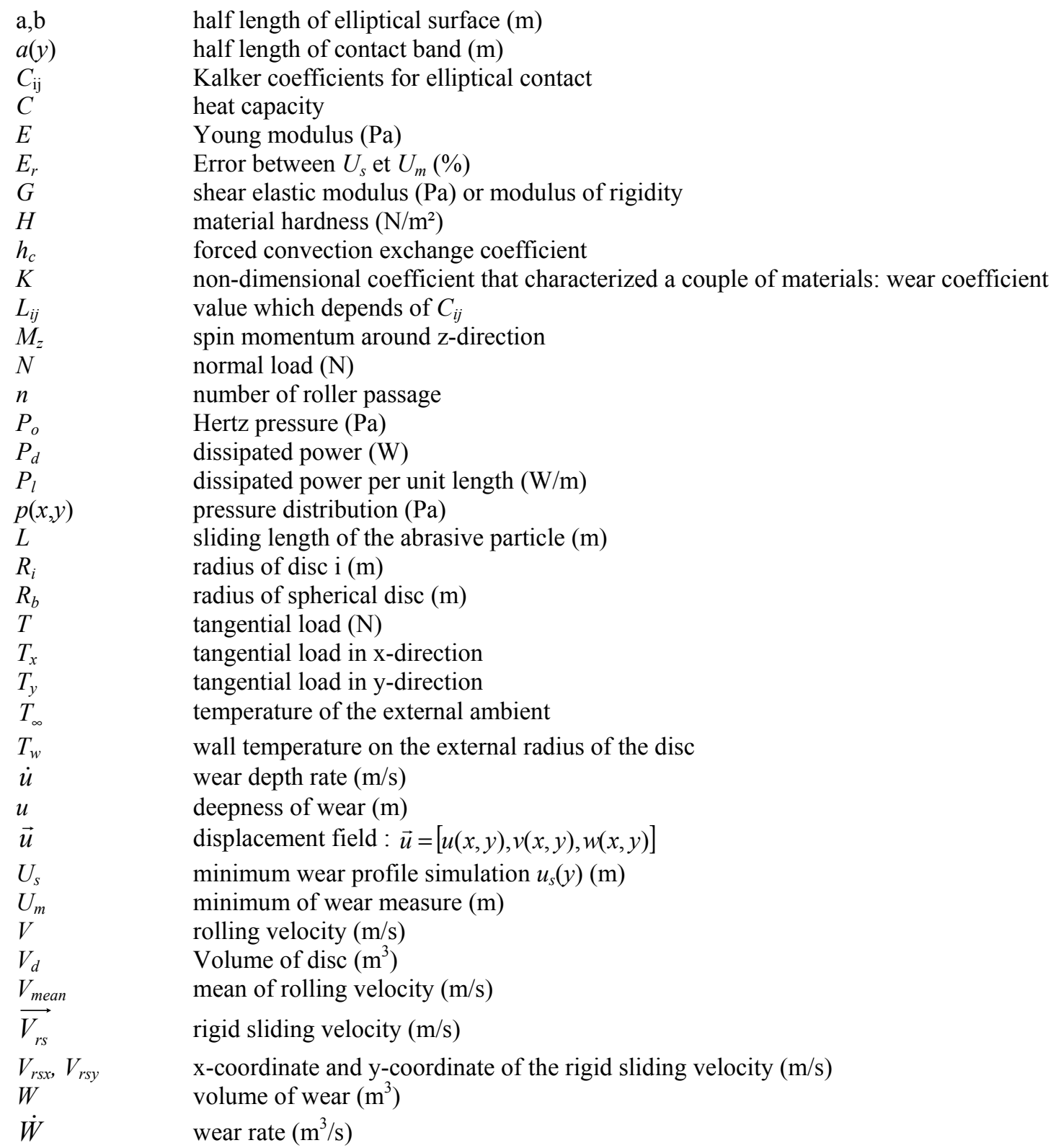




$\begin{array}{ll}w(x, y) & \text { sliding velocity }(\mathrm{m} / \mathrm{s}) \\ w_{x} & \text { sliding velocity in } \mathrm{x} \text {-direction }(\mathrm{m} / \mathrm{s}) \\ w_{y} & \text { sliding velocity in y-direction }(\mathrm{m} / \mathrm{s})\end{array}$

$\begin{array}{ll}\text { Greek letters } & \\ \lambda & \text { thermal conductivity } \\ \mu & \text { friction coefficient } \\ \mu_{a} & \text { apparent friction coefficient } \\ v & \text { Poisson's ratio } \\ v_{\mathrm{x}} & \text { longitudinal creep coefficient } \\ v_{\mathrm{y}} & \text { transversal creep coefficient } \\ \tau(x, y) & \text { tangential traction }(\mathrm{Pa}) \\ \tau_{x} & \text { tangential traction in } \mathrm{x} \text {-direction }(\mathrm{Pa}) \\ \tau_{y} & \text { tangential traction in } \mathrm{y} \text {-direction }(\mathrm{Pa}) \\ \phi & \text { spin in the contact area }\left(\mathrm{m}^{-1}\right) \\ \varphi_{x}, \varphi_{y} & \text { angular defect of positioning body }(\mathrm{rad}) \\ \omega_{i} & \text { rotating velocity }(\mathrm{rad} / \mathrm{s}) \text { of disc } \mathrm{i}\end{array}$

\section{List of figures}

Figure 1: Twin-disc apparatus. Rotation rates are imposed to both discs and slip can be controlled. Normal load $\mathrm{N}$ between the two discs is constant during the test and tangential load $\mathrm{T}$ is measured continuously. Rotation rate is about $3000 \mathrm{rpm}$. The velocity of the contact point is about $9.5 \mathrm{~m} / \mathrm{s}$.

Figure 2: Longitudinal creep (slip rate) and traction coefficient $\mathrm{T} / \mathrm{N}$ versus time respectively imposed and measured during the twin disc experimentation in ambient air and in cryogenic ambient

Figure 3: Potential contact area considered to solve the exact problem. d(MM') is the relative displacement between two points $\mathrm{M}$ and $\mathrm{M}^{\prime}$.

Figure 4: Reference solution of the steady state rolling contact computed from the exact problem. One can observe the linearity of the relative speed $w_{x}$ in the slipping zone (a). In the adhesive zone, one can observe the non linear evolution of tangential traction $\tau_{x}(\mathrm{~b})$.

Figure 5: Steady state rolling contact twin disc problem solved using Fastsim approximation. One can observe a large adhesive zone (larger than the reference solution of Fig. 4). The relative speed $w_{x}$ is linear in the slipping zone (a). The tangential traction $\tau_{x}$ is linear in the adhesive zone (b). Both distributions are very similar to the reference solution and give less than $1 \%$ difference on the dissipated power $P_{d}$ during rolling.

Figure 6: Apparent coefficient of friction $\mu_{a}$ versus longitudinal creep for $\mu=0.6$. Experimental values of ambient air test are superposed (diamonds) and follow approximately the same evolution. The partition between slipping zone and adhesive zone is illustrated for several longitudinal creepage values. When slip occurs on the complete contact area the apparent coefficient of friction $\mu_{a}$ is equal to the real coefficient of friction $\mu$.

Figure 7: Friction coefficient versus longitudinal creep identification chart. Guide lines are plotted for $\mu$ values varying from 0.05 to 0.7 step of 0.05 , measured coefficient of friction are given by diamonds for air conditions and triangles for cryogenic conditions. One can observe that the coefficient of friction is very small in cryogenic conditions until longitudinal creepage remains less than $3 \%$.

Figure 8: Modelling of the creepage history during the wear experiment and corresponding modelled coefficient of friction used for the numerical simulation of the wear evolution during the test. In Ambient air case and in liquid Nitrogen case. The second experiment duration is a little shorter.

Figure 9: Rolling zone profile for disc 1 after the experiment for $\mathrm{N}=72 \mathrm{~N}$ in ambient air (top) and in Liquid nitrogen condition (bottom). One can see that wear depth is lower for cryogenic condition than for ambient air condition, which is easily justified by the lower value of the mean friction ratio during the test and the smaller duration of the same test.

Figure 10: Description of the contact area in Hertzian problem. The rolling direction is in $\mathrm{x}$-direction

Figure 11: Presentation of the algorithm which was used to identify the wear coefficient $K$ 
Figure 12: Maximum wear depth during the twin disc test. These curves are obtained by numerical simulation for the two cases (ambient temperature and liquid nitrogen) using a unique wear factor (no dependence of temperature on the wear law).

Figure 13: Temperature evolution during twin-disc experiment (numerical simulation). Case (a) ambient air condition, $T_{\infty}=20^{\circ} \mathrm{C}$. Case (b) cryogenic condition, $T_{\infty}=-196^{\circ} \mathrm{C}$. In both cases increase of temperature does not exceed $10^{\circ} \mathrm{C}$. This small increase is not sufficient to explain friction ratio instability during the cryogenic test.

Figure 14: Measured wear of cylindrical disc profile compared with the result of numerical simulation (cryogenic condition case). The maximum depth is well reproduced but the wear width is under estimated by the numerical simulation.

\section{References}

[1] M. Quillien, R. Gras, L. Collongeat, Th. Kachler, 'A testing device for rolling-sliding behavior in harsh environments : the twin-disk cryotribometer' Trib. Int. 34 (2001) 287-292

[2] A.E.H. Love, 'A treatise on the theory of elasticity', $4^{\text {th }}$ Ed. Cambridge University press (1926)

[3] K.L. Johnson, 'Contact Mechanics', Cambridge University Press (1985)

[4] J. J. Kalker, 'Three-Dimensional Elastic Bodies in Rolling Contact', Kluwer Academic (1991)

[5] R.D. Mindlin, 'Compliance of elastic bodies in contact',ASME J. Appl. Mech. (1949), 259-268

[6] B. Jacobson, J.J. Kalker, 'Rolling Contact Phenomena', CISM Lecture No. 411, Springer, Berlin (2000).

[7] J. J. Kalker, 'A Fast Algorithm for the Simplified Theory of Rolling Contact', (program FASTSIM), Vehicle Systems Dynamics, Vol. 11 pp 1-13, SWETS \& ZEITLINGER B.V. - LISSE, (1982)

[8] H. Hertz, 'Über die berührung fester elasticher körper (on the contact of elastic solids)', J. Reine und Angewandte Mathematik 92, (1882) 156-171, translated and reprinted in Hertz's Miscelaneous Papers, MacMillan \& Co, London, (1896).

[9] L.Chevalier et H.Chollet, 'Endommagement des pistes de roulement', Mec. Ind.(2000) 1, 593-602

[10] W.Kik, J.Piotrowski, 'A fast approximate method to calculate normal load at contact between wheel and rail, and creep forces during rolling', Warsaw Technical University, 2nd mini-conference on contact mechanics and wear of rail/wheel systems, Budapest, July 29-31 (1996)

[11] Zi-Li Li, Kalker J.J., 'Simulation of Severe Wheel-Rail Wear', Delft University 1996

[12] J.F. Archard, 'Contact and rubbing of flat surfaces', J.Appl. Phys. 24 (1953), 981-988

[13] E.Felder, 'Mécanismes physiques et modélisation mécanique du frottement entre corps solides', Mec. Ind. 12 (2000) 555-561

[14] D.François, A.Pineau, A.Zaoui, 'Comportement mécanique des matériaux, tome 2', Hermès (1993), 401450 159-166

[15] Z.L.Li, J.J.Kalker, 'Computation of wheel-rail conformal contact', Proc. of 4th world cong. on computational mechanics, BuenosAires, (July 1998)

[16] Ayasse J.B., Chollet H., 'Determination of the wheel rail contact patch in semi-Hertzian conditions, Vehicle Systems Dynamics, 43, 3 (2005) 161-172 


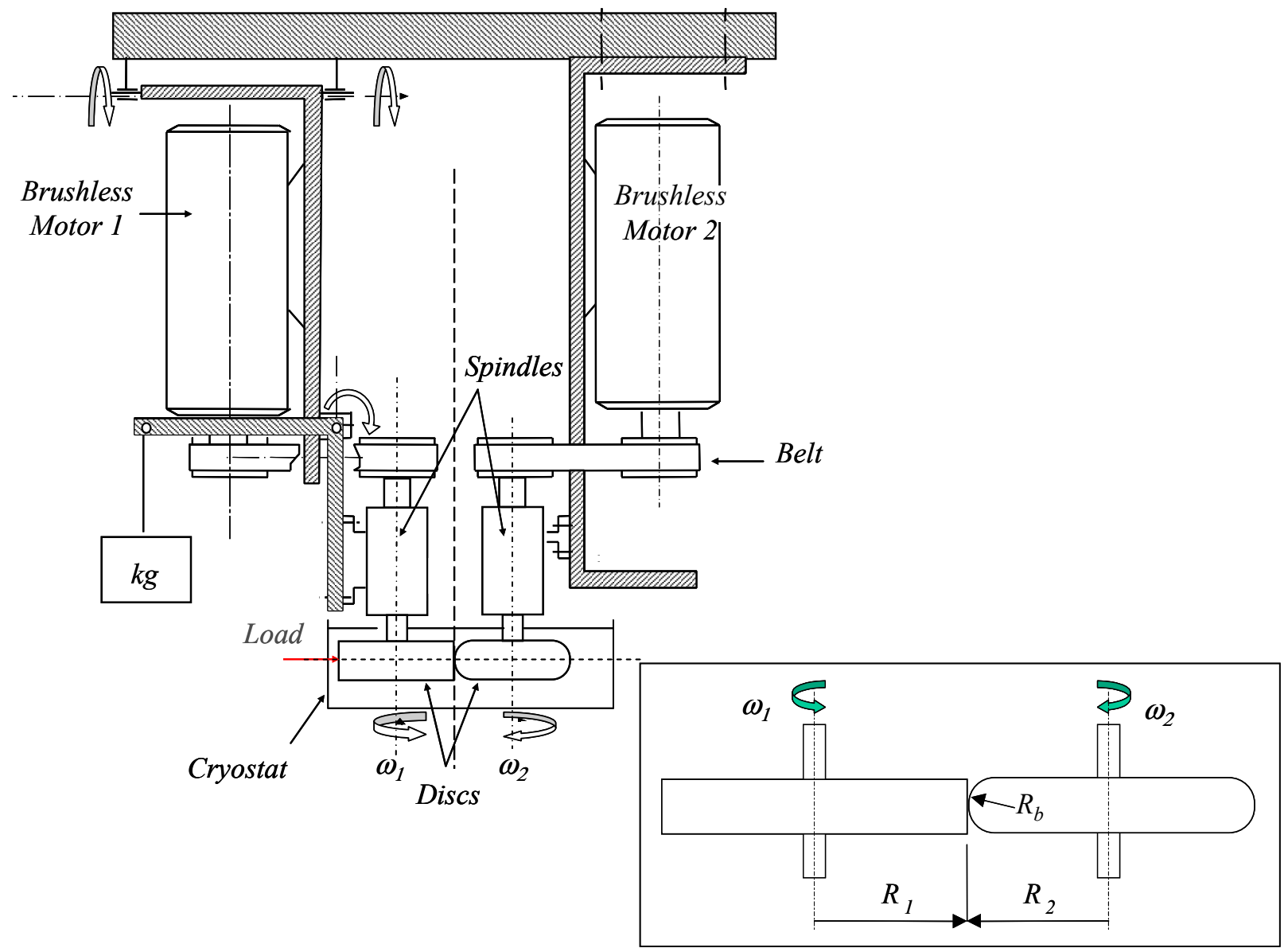

Figure 1: Twin-disc apparatus. Rotation rates are imposed to both discs and slip can be controlled. Normal load $\mathrm{N}$ between the two discs is constant during the test and tangential load $\mathrm{T}$ is measured continuously. Rotation rate is about $3000 \mathrm{rpm}$. The rolling velocity of the contact point is about $9.5 \mathrm{~m} / \mathrm{s}$. 

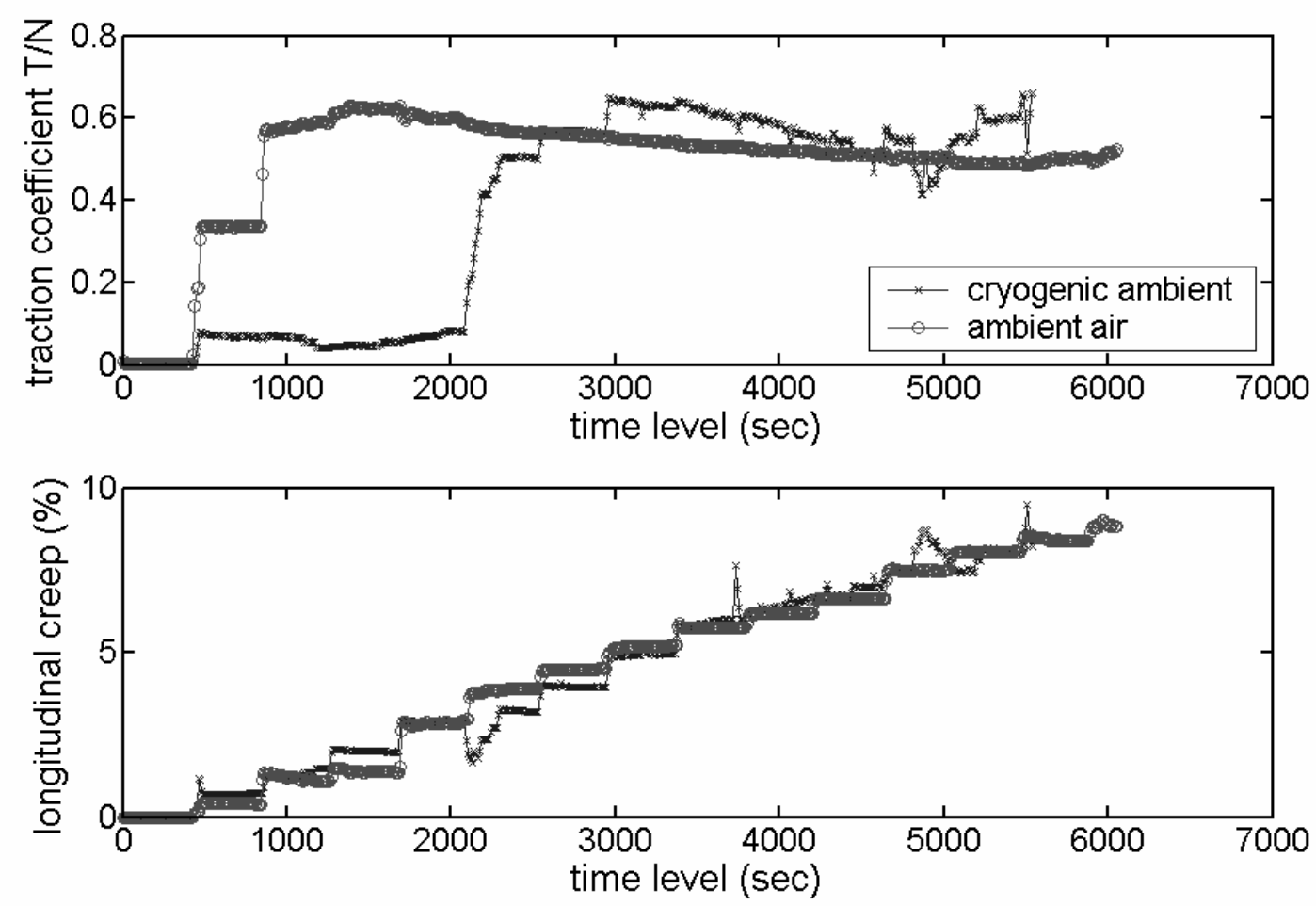

Figure 2: Longitudinal creep (slip rate) and traction coefficient $\mathrm{T} / \mathrm{N}$ versus time respectively imposed and measured during the twin disc experimentation in ambient air and in cryogenic ambient. Ambient air test is marked by (o) and cryogenic ambient test is marked by (x). 


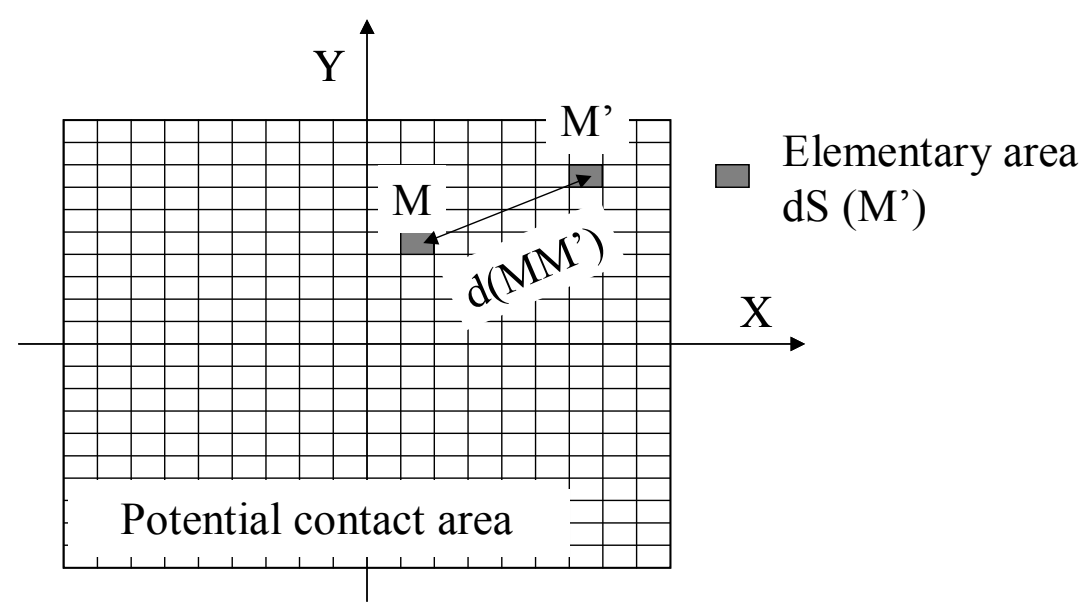

Figure 3: Potential contact area considered to solve the exact problem. The distance d(MM') between two points $\mathrm{M}$ and $\mathrm{M}$ ' is noted ' $\mathrm{r}$ ' in the text: $\mathrm{d}\left(\mathrm{MM}^{\prime}\right)=r=\sqrt{\left(x-x^{\prime}\right)^{2}+\left(y-y^{\prime}\right)^{2}}$. 


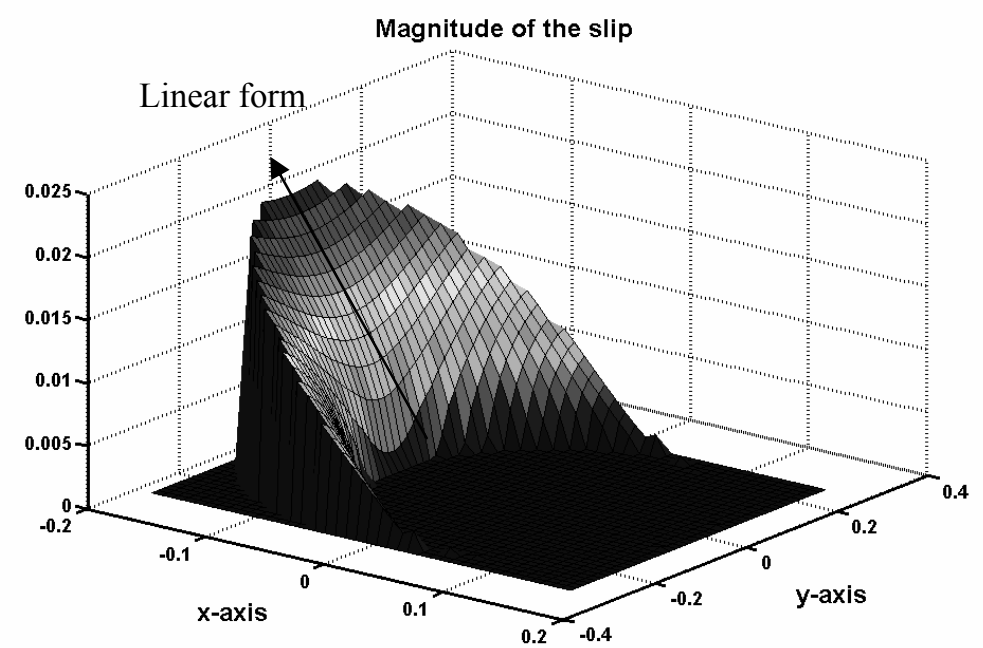

(a)

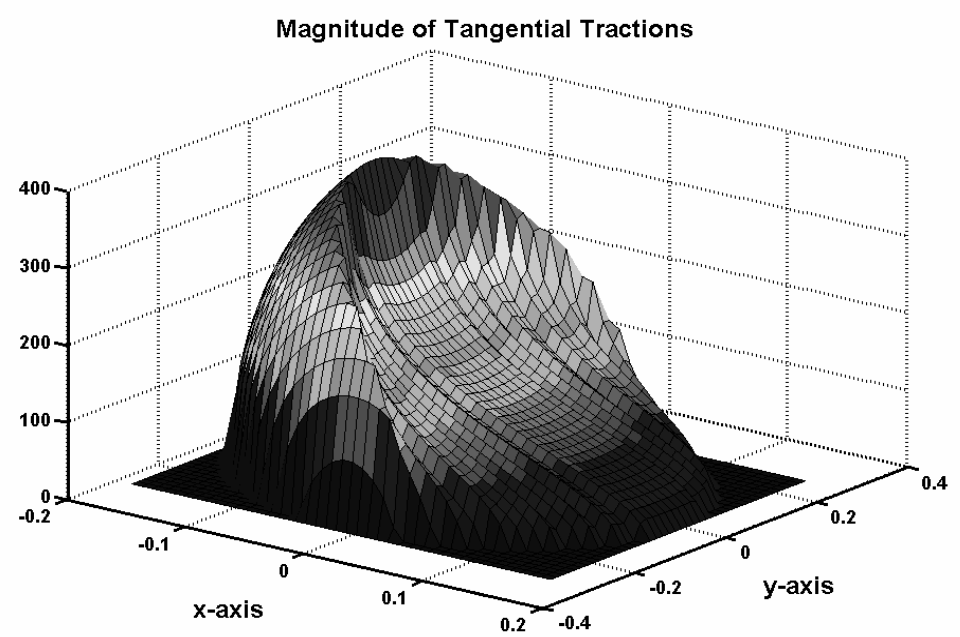

(b)

Figure 4: Reference solution of the steady state rolling contact computed from the exact problem. One can observe the linearity of the relative speed $w_{x}$ in the slipping zone (a). In the adhesive zone, one can observe the non linear evolution of tangential traction $\tau_{x}(b)$. 


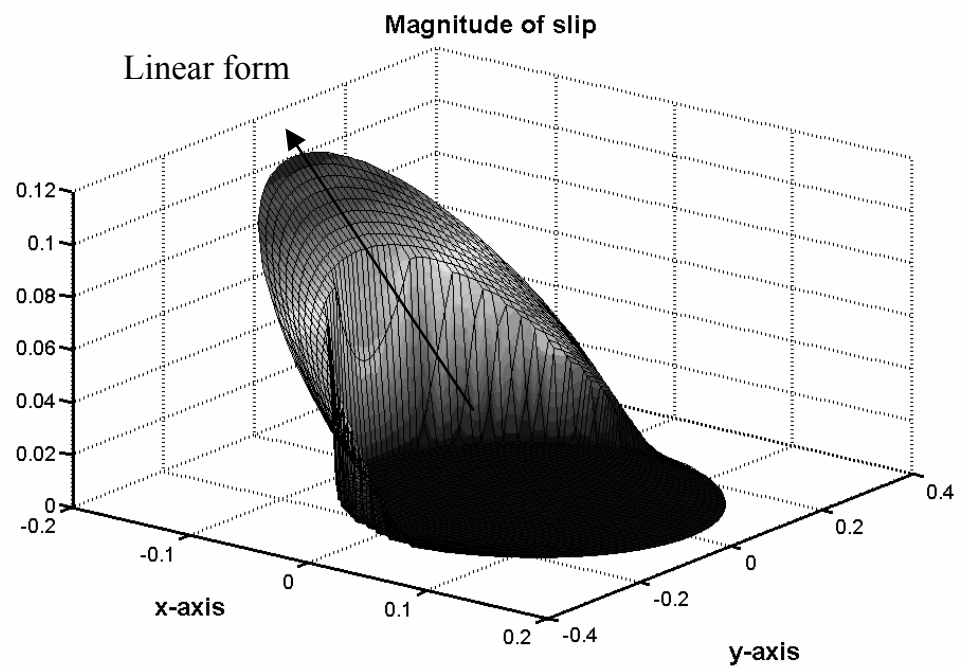

(a)

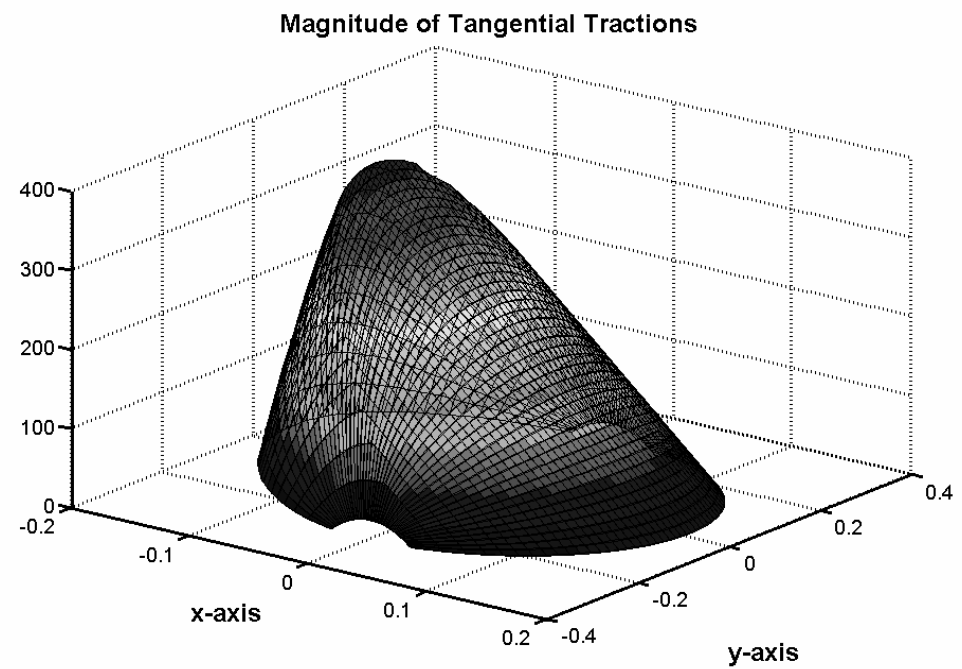

(b)

Figure.5: Steady state rolling contact twin disc problem solved using Fastsim approximation. One can observe a large adhesive zone (larger than the reference solution of Fig. 4). The relative speed $w_{x}$ is linear in the slipping zone (a). The tangential traction $\tau_{x}$ is linear in the adhesive zone (b). Both distributions are very similar to the reference solution and give less than $1 \%$ difference on the dissipated power $P_{d}$ during rolling. 


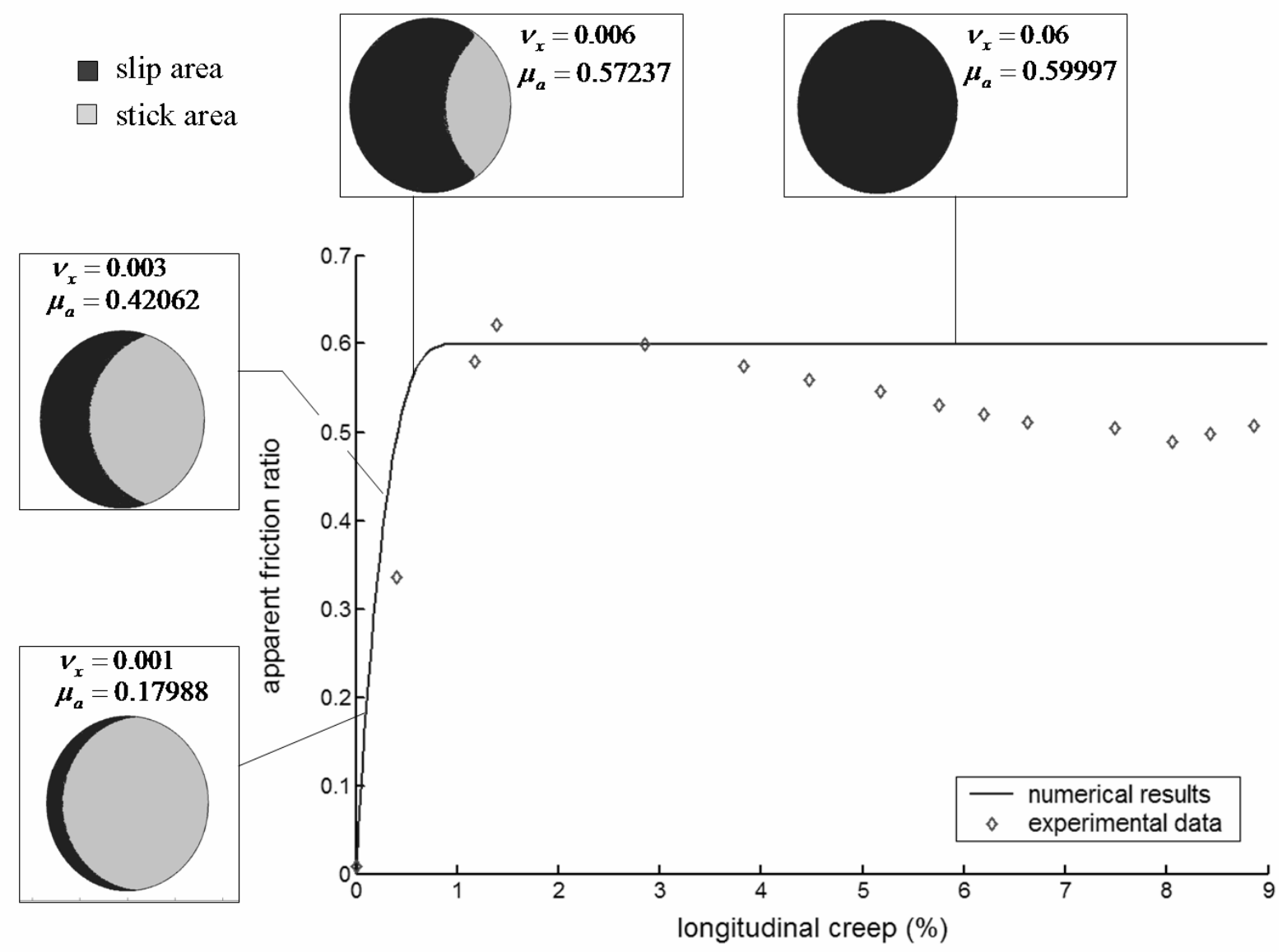

Figure 6: Apparent coefficient of friction $\mu_{a}$ versus longitudinal creep for $\mu=0.6$. Experimental values of ambient air test are superposed (diamonds) and follow approximately the same evolution. The partition between slipping zone and adhesive zone is illustrated for several longitudinal creepage values. When slip occurs on the complete contact area the apparent coefficient of friction $\mu_{a}$ is equal to the real coefficient of friction $\mu$. 


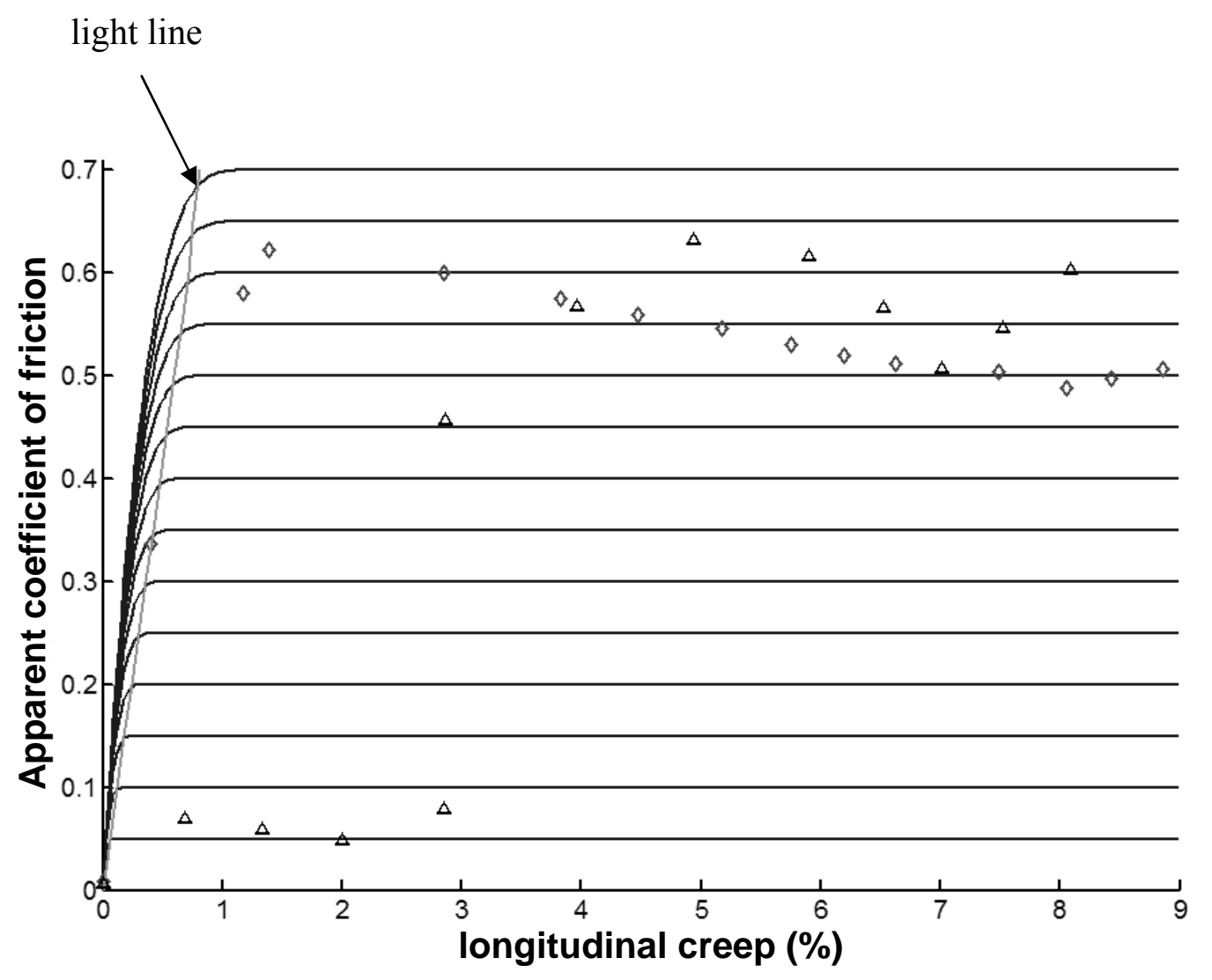

Figure 7: Friction coefficient versus longitudinal creep identification chart. Guide lines are plotted for $\mu$ values varying from 0.05 to 0.7 step of 0.05 , measured coefficient of friction are given by diamonds for air conditions and triangles for cryogenic conditions. One can observe that the coefficient of friction is very small in cryogenic conditions until longitudinal creepage remains less than $3 \%$. 

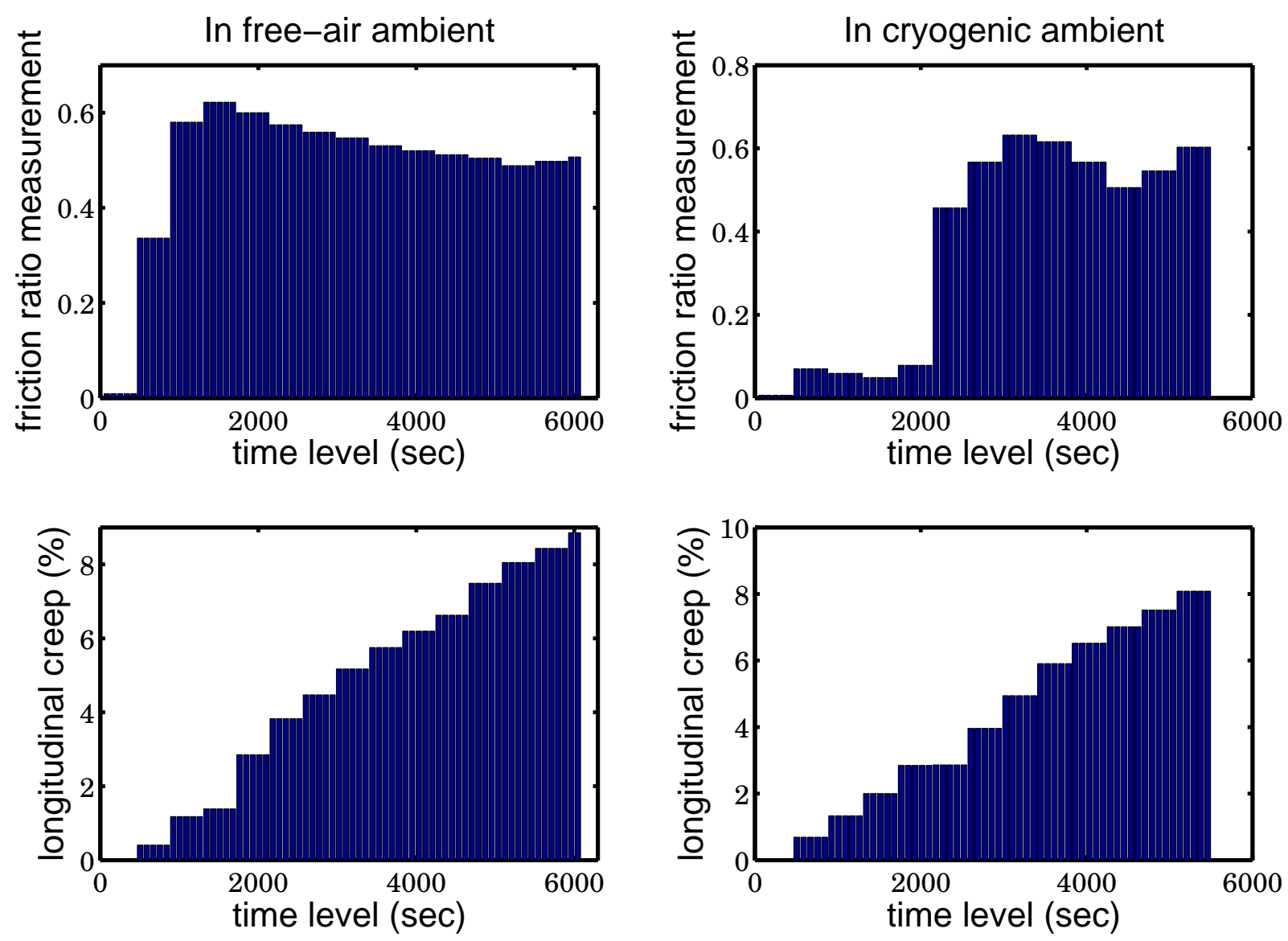

Figure 8: Modelling of the creepage history during the wear experiment and corresponding modelled coefficient of friction used for the numerical simulation of the wear evolution during the test. In Ambient air case and in liquid Nitrogen case. The second experiment duration is a little shorter. 

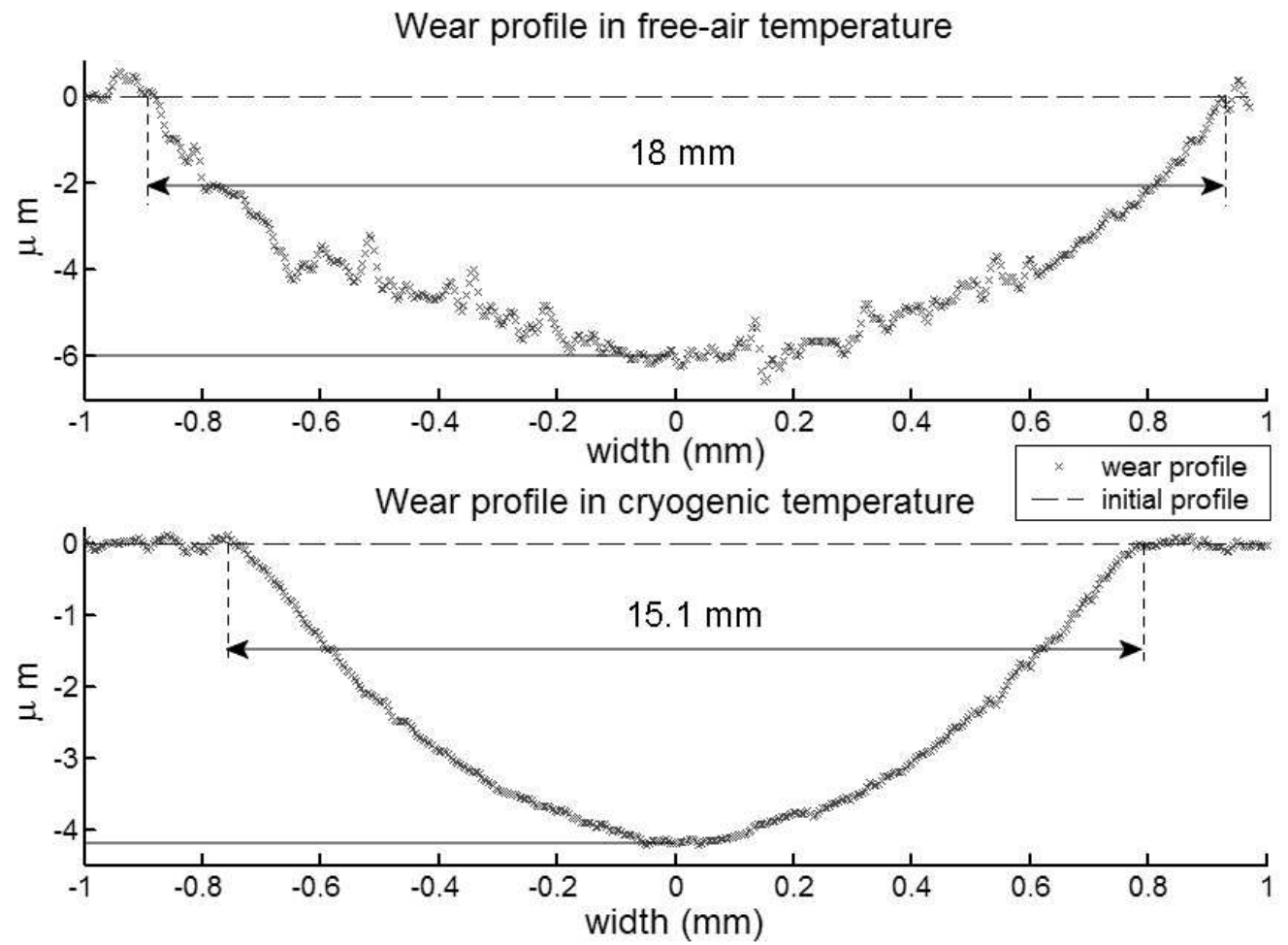

Figure 9: Rolling zone profile for disc 1 after the experiment for $\mathrm{N}=72 \mathrm{~N}$ in ambient air (top) and in Liquid nitrogen condition (bottom). One can see that wear depth is lower for cryogenic condition than for ambient air condition, which is easily justified by the lower value of the mean coefficient of friction during that test and the smaller duration. 


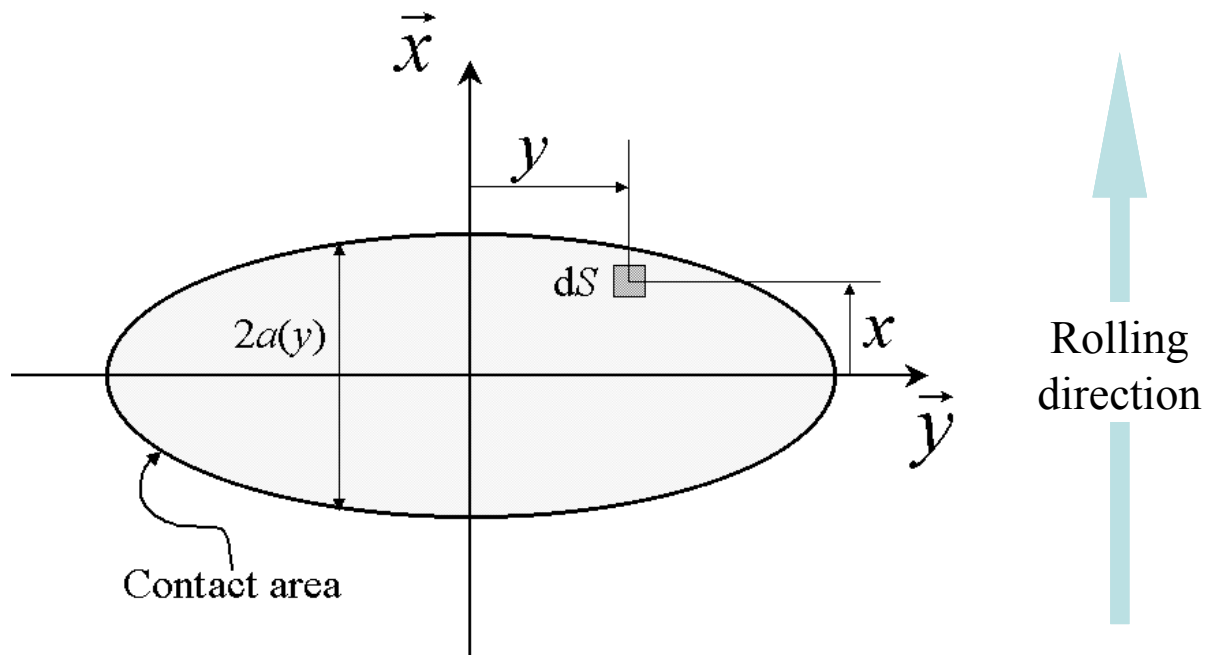

Figure 10: Description of the contact area in Hertzian problem. The rolling direction is $\mathrm{x}$-direction 


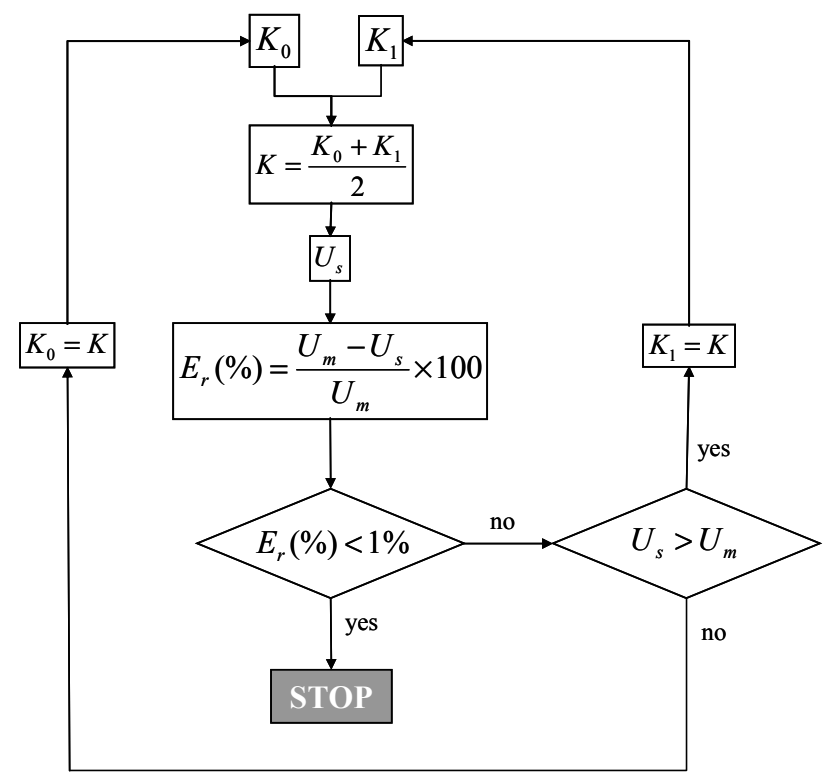

Figure 11: Presentation of the algorithm which was used to identify the wear coefficient $K$. 


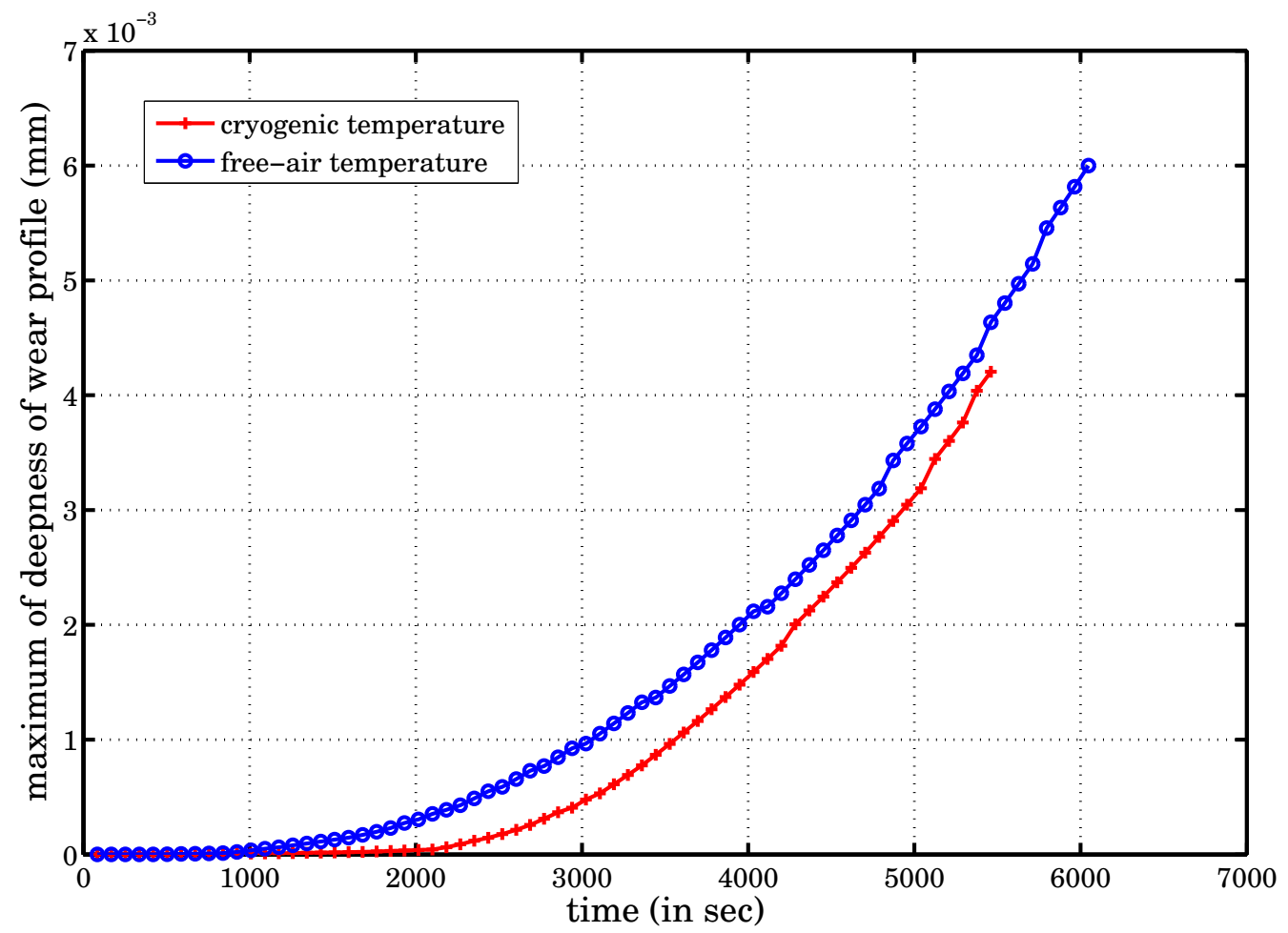

Figure 12: Maximum wear depth during the twin disc test. These curves are obtained by numerical simulation for the two cases (ambient temperature and liquid nitrogen) using a unique wear factor (no dependence of temperature on the wear law). 


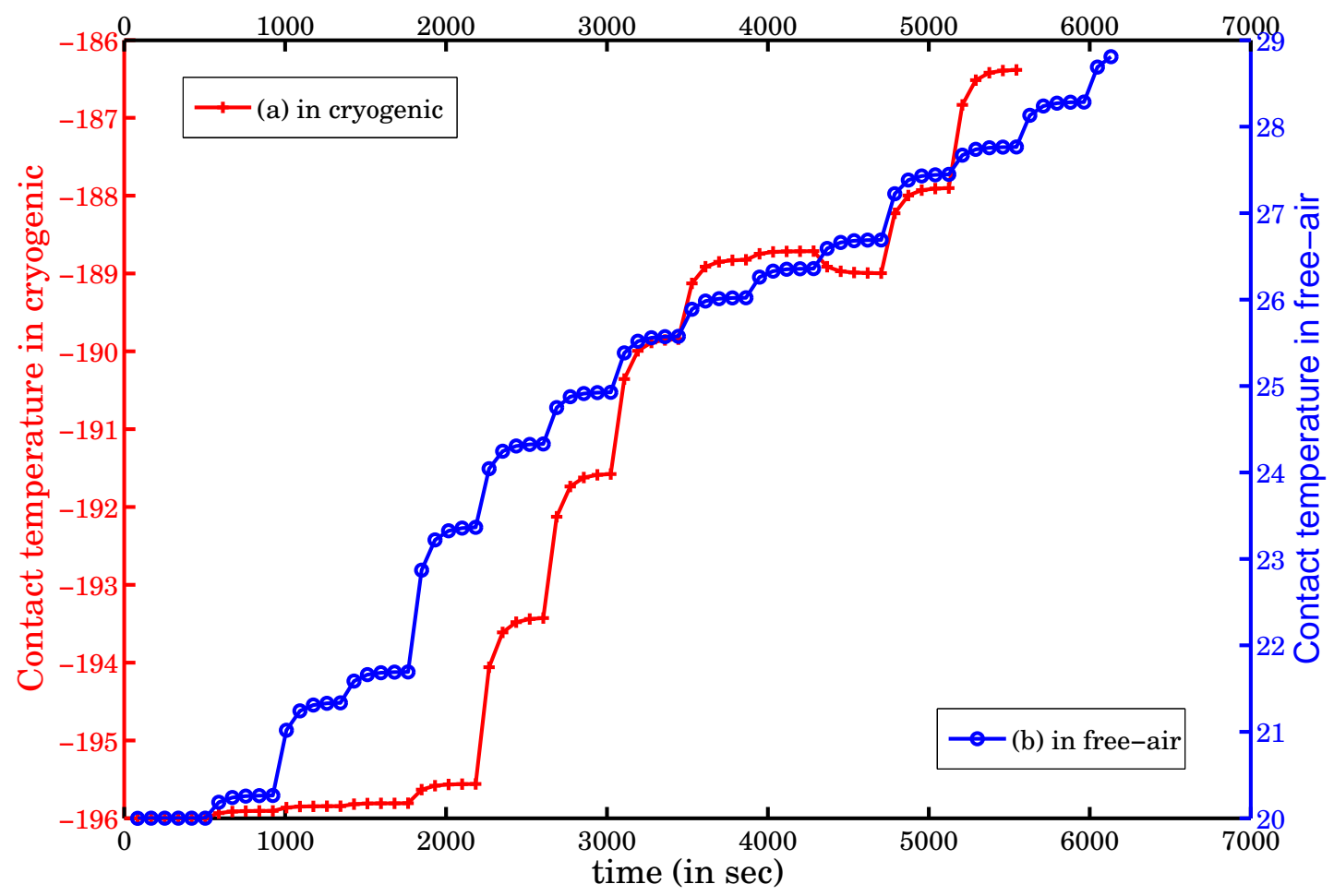

Figure 13: Temperature evolution during twin-disc experiment (numerical simulation). Case (a) ambient air condition, $T_{\infty}=20^{\circ} \mathrm{C}$. Case (b) cryogenic condition, $T_{\infty}=-196^{\circ} \mathrm{C}$. In both cases increase of temperature does not exceed $10^{\circ} \mathrm{C}$. This small increase is not sufficient to explain coefficient of friction instability during the cryogenic test. 


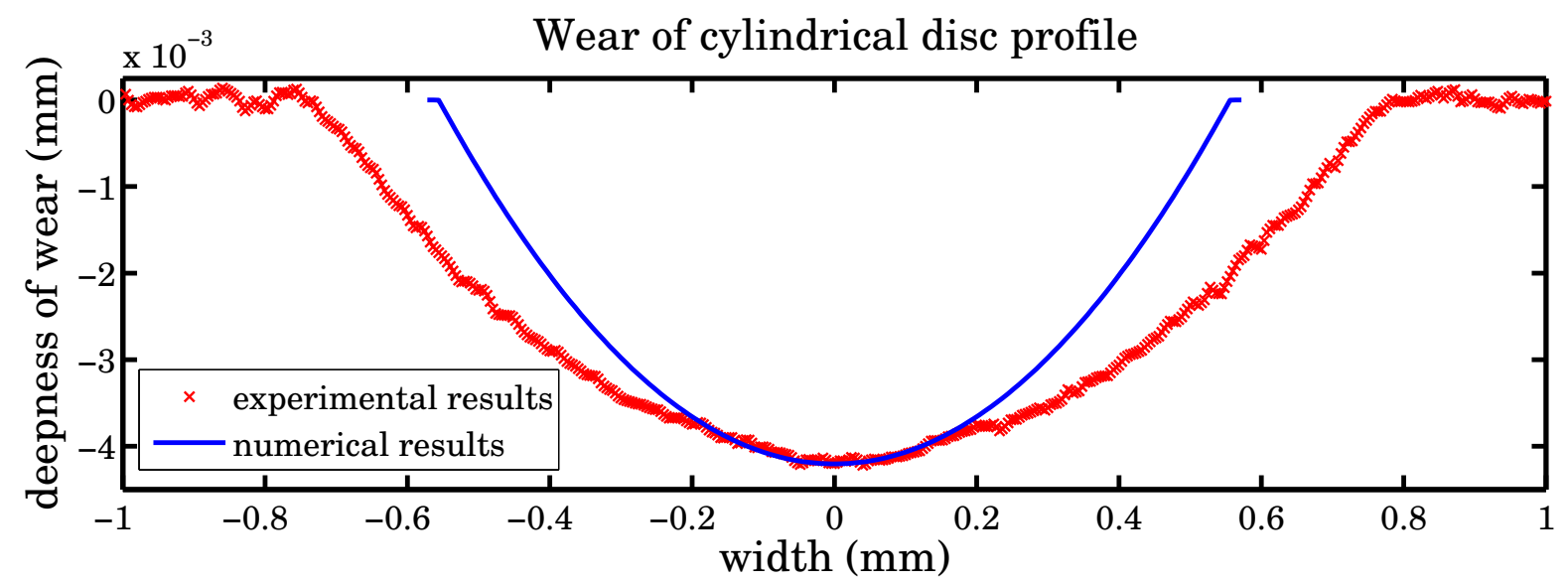

Figure 14: Measured wear of cylindrical disc profile compared with the result of numerical simulation (cryogenic condition case). The maximum depth is well reproduced but the wear width is under estimated by the numerical simulation. 